\title{
Geographic Location and Linguistic Diversity: The Use of Intensifiers in Egyptian and Saudi Arabic
}

\author{
Abdulfattah $\operatorname{Omar}^{1} \&$ Mansour Alotaibi ${ }^{2}$ \\ ${ }^{1}$ Department of English, College of Science and Humanities, Prince Sattam bin Abdulaziz University, Saudi \\ Arabia \\ ${ }^{2}$ Department of Arabic, College of Education, Prince Sattam bin Abdulaziz University, Saudi Arabia \\ Correspondence: Abdulfattah Omar, Department of English, College of Science and Humanities, Prince Sattam \\ bin Abdulaziz University, Al-Kharj 11942, Saudi Arabia. E-mail: a.a.omar2010@gmail.com
}

Received: April 12, 2017 Accepted: May 8, 2017 Online Published: July 16, 2017

doi:10.5539/ijel.v7n4p220 URL: http://doi.org/10.5539/ijel.v7n4p220

\begin{abstract}
Numerous studies have indicated that geographic location plays an essential role in language variation and the emergence of dialects. That is, when speakers of the same group are geographically apart, it is more likely that they use language differently. The unprecedented widespread of communication channels in what is referred to now as the global age, however, has raised many doubts in relation to the connection between space and geographic location on the one hand and language variation on the other hand. In other words, many linguists have come to question the rationality of geographic location in language variation. In the face of this controversial issue, the purpose of this study is to investigate the influence of geographic location on linguistic diversity in relation to Arabic. The study is limited in scope. It is only concerned with the use of intensifiers in the spoken forms of Egyptian and Saudi spoken Arabic. The rationale is that intensifiers are very frequent in everyday communication and occur naturally without much thinking on the part of speakers. In order to achieve this objective, the study is based on a corpus of selections from the Egyptian radio show Ish Sabahak (Live Your Morning) on Nogoum FM Radio Channel and the Saudi radio show Caffeine on Mix FM. Results indicate clearly that there are linguistic differences between Egyptian and Saudi speakers in the use of intensifiers in terms of frequency, type, and the linguistic structure. This suggests that distance or geographic location is still a considerable factor in linguistic diversity since it is deeply rooted in the cultural evolution of people from different nations.
\end{abstract}

Keywords: geographic location, dialects, linguistic diversity, Egyptian Arabic, Saudi Arabic

\section{Introduction}

The role of geographic location in linguistic diversity and the development of regional dialects has always been a recurrent topic in sociolinguistic studies. For years, it was believed that geographic location or distance had a considerable effect on the way people use language and hence the emergence of regional dialects (Holmes, 2008; Wardhaugh, 2006; Wardhaugh \& Fuller, 2015). These studies and the like are now referred to as research traditions in sociolinguistics. With the emergence of globalization and the development of unprecedented communication channels between people, different studies have come to raise doubts in relation to the effect of geographic location on linguistic diversity. The main argument is that geographic location has no connection with language variation (Auer, 2013; Auer \& Schmidt, 2010; Beal, 2010). In the face of this, this article investigates the role of geographic location on language use in Egyptian and Saudi Arabic. The study is based on a corpus of colloquial spoken Egyptian and Saudi Arabic. Data is abstracted from two radio shows. These are (1) the Egyptian radio show Ish Sabahak (Live Your Morning) on Nogoum FM Radio Channel and (2) the Saudi radio show Caffeine on Mix FM.

\section{Previous Work}

Numerous studies have been concerned with the relationship between geographic location and linguistic diversity. This is usually referred to in the literature as regional variation linguistics, a subdiscipline within sociolinguistics (Beal, 2010; Hargraves, 2003; Hughes, \& McArthur, 2002; Peters, 2007; Trudgill \& Hannah, 2008; Trudgill, \& Watt, 2015). The main argument of these studies indicates that there are significant linguistic 
differences within languages in general and that geographic location or space plays an important role in linguistic diversity. Some studies even go beyond indicating that in spite of globalization and the increasing advancement in telecommunication tools, features of dialect are still clear markers of regional and local identity (Beal, 2010).

According to Trousdale (2010), all languages have dialectical variations. These variations, or dialects, can differ in phonology, morphology, spelling, vocabulary, and/or syntax from the standard language that many people often think of wrongly as the "correct" language. He asserts that geographic background has a significant role in linguistic diversity. In the same way, Syal \& Jindal (2007) argue that languages vary from one place to another where speakers of the same language use it differently based on the place where they live. Beal (2010) agrees that geographic location leads to the emergence of dialectal variations within a language. These variations, however, are governed by mutual intelligibility where speakers of a language can understand each other. The study of language variation, or what is technically referred to as dialects, is the concern of dialectology, a discipline in sociolinguistics. The emergence of dialects or language variation can be attributed to some primary factors. These include geographic location, class, education, occupation, ethnicity, sex, and age (Matras, 2009; Wardhaugh, 2006). This article, however, is concerned with regional differences in relation to spoken Arabic. To put it into effect, the study investigates the differences between Egyptian and Saudi Arabic concerning the use of intensifiers.

In regional variation, the assumption is that there is a connection between language and space or location. Numerous studies have indicated that geographic location plays an essential role in language variation and the emergence of dialects. That is, when speakers of the same group are geographically apart, it is more likely that they use language differently. In England, for instance, geographic location is an important element in identifying the dialects that are spoken over the country. English speakers in the North East, for instance, pronounce bus as /bus/, which is different from RP. It is also claimed that space and location have been essential in the emergence of a new variety of English that came to be known as General American English which is different from the UK varieties. Historically, when people moved from England to America, they brought their language with them. However, for contact and communication reasons, the English they used to speak began to change in different ways. One main change was the adoption of local forms on the level of vocabulary and the takeover of lexemes from other languages. Increasingly, American English as a language drew on its own resources and became less and less dependent on the English motherland (Algeo, 2010). Today there are so many differences between British and American English. It is always said: "two nations divided by a common language", a saying which is attributed to many including Dylan Thomas, Winston Churchill, George Bernard Shaw and Oscar Wilde. The implication is that barriers of geographic location become linguistic barriers. The emergence of linguistic differences due to time and distance relation is referred to in the literature as "contagious diffusion" (Wolfram \& Schilling, 2016, p. 144). The implication here is that the emergence of dialectal variations is bound to the movement of a language from one place to another. In our case, Arabic moved from Arabia to Egypt and this movement has brought about different linguistic differences.

Some linguists even go further arguing that some language aspects are related in one way or another to the geographic location and the environment where people live (Everett, 2013; Everett, Balsi, \& Roberts, 2015; Lass, 1997). According to Everett (2013), for instance, geographic location or context has a direct impact on phonological forms of language. Examining the geographic features of 567 language locations worldwide, Everett stresses that there is a direct influence of the geographic context on the phonological features and characteristics of human languages. This agrees with numerous studies that indicate that there is a correlation between geographic location and language constructs. Some argue that people who live in isolated islands usually speak languages that are characterized by simple phonology and phonetics. Others argue that languages in the north generally have more consonants and stress while those in the south generally have tones and are more syllable-timed. The implication for this study is that geographic patterns play a significant role in linguistic diversity (Gavin et al., 2013).

The widespread and accessibility of communication channels in the global age, however, have raised many doubts in relation to the connection between space and geographic location from one hand and language variation on the other hand. In other words, many linguists have come to question the rationality of location in language variation. Auer (2013), for instance, stresses that there is no connection between geographic location and language variation. The implication is that the boundaries that used to be between nations do not exist today. As a result, the claim that linguistic differences rest on geographic location seems unsupported.

Rallings (2015) argues that the increasing interaction and the recent proliferation access and use of social media accessible have their implications on the way people use language. With these new global changes, regional 
dialects are reduced to its lowest levels. She adds that communication through social media sites such as Twitter and Facebook put an end to the geographical and cultural divisions of the physical country. A good example for this argument is the use of abbreviations on blogs, emails, and other social media sites. This is a process where speakers tend to shorten words to single letters and eliminate vowels from some words.

Tadmor (2009) even goes beyond arguing that English speakers from different parts of the world use abbreviations like in the same way. It is even argued that the internet is developing a standard informal writing system (Gibson, 2013). The implication is that speakers of a language are now part of one huge web community with a shared lexicon. Those speakers tend to use language in the same way. This entails that the younger generation of internet users are more likely to use language in a more similar way regardless of geographic distances and political boundaries. The internet, together with other factors that include satellite TV channels and mobile phones, is now shaping the way language is used by its community speakers. In the Arab world, for instance, the increasing use of the internet and the explosion of communications over social media sites have opened the door to a completely new way of language use. The new way of writing adopted by millions of Arabic speaking users of the internet indicates that geographic location has nothing to do with the way speakers use language.

In terms of spoken Arabic, it is argued that the increasing contact between speakers of Arabic narrowed the linguistic gaps always found as a result of the emergence of regional dialects. In his interface of Egyptian and Saudi Arabic, Mubarak \& Darwish (2014) argue that the emergence of Egyptian satellite channels in the closing years of the 20th century, the increasing numbers of Egyptians working in Saudi Arabia, and the unprecedented contact between Egyptians and Saudis on social media sites have influenced the everyday language of Saudis significantly. Saudi Arabic has acquired many linguistic features from Egyptian Arabic that can be seen quite obviously in the use of intensifiers, swear words, and address terms. He concludes that geographic location has nothing to do now with linguistic diversity. Likewise, Maffi (2005) argues that in the age of globalization, geographic location is not a significant factor in linguistic diversity. He explains that vernacular varieties of Arabic are coming very close to each other. He asserts that many linguistic features that used to differentiate vernacular dialects have disappeared in the speeches of the younger generations of Arab speakers.

\section{Research Questions}

In the light of the above argument, this article is concerned with exploring the use of intensifiers in contemporary Egyptian and Saudi spoken Arabic. It tends to see whether there are significant differences in the use of intensifiers. The rationale of selecting intensifiers is that they occur naturally; that is, speakers do not think a lot before saying them. Furthermore, they are very frequent in everyday communication. Therefore, they provide a unique opportunity for investigating linguistic innovation and how language is used differently by people (Tagliamonte \& Roberts, 2005). In other words, the study of intensifiers can be useful in identifying internal and external factors that determine language variation.

This article addresses these research questions: (1) Which intensifiers are most commonly used in contemporary Egyptian and Saudi Arabic? (2) Are there any differences between contemporary Egyptian and Saudi Arabic in the use of intensifiers? If so, does location or space have any impact in this language variation?

\section{Intensifiers: Features and Functions}

Speakers tend to use specific words such as very, really, amazingly, particularly and extremely in order to make adjectives stronger. These adverbs of degree can be classified under the heading intensifiers. Generally speaking, intensifiers are degree words that scale a quality up or down to a certain degree. According to Quirk et al. (1985), intensifiers are used in order to strengthen or weaken the meaning of the adjective that is modified. They bring the quality that is expressed by the adjective to a degree somewhere between the two far ends of a degree scale. Intensifiers, Klemola (2013, p. 82) argues, are stressed and are used to "assign prominence to some constituent of a sentence". In this, Gast (2006) stresses that intensifiers are best described in terms of their semantic and prosodic features.

Intensifiers exist in almost all languages with different degrees. Gast (2006) argues that "most Germanic languages including English have intensifiers" (2006, p. 1). In English, intensifiers can be classified under three main categories. These are

(1) Adverbs such as really, very, so, absolutely, amazingly, remarkably, exceptionally, incredibly, particularly, unusually, completely and heartily. These are used to boost the quality expressed by an adjective positively, or to bring it to a lower degree.

(2) -self forms such as myself, himself, herself, and so on, and 
(3) A group of other specific expressions such as on one's own accord, on one's own, bloody, etc.

Unlike English and other German languages, intensifiers are not common in Arabic. in this context, we need to distinguish between Classical Arabic and Modern Standard Arabic. Classical Arabic is not normally used today. It has been replaced by what is referred to as MSA. This is the formal version of Arabic and it is used in all formal contexts. Along with MSA, there are the colloquial spoken dialects that emerged as a result of language contact between Arabs and other nations over the last 14 centuries. Colloquial dialects include among many other regional dialects Egyptian and Saudi Arabic.

In Classical Arabic, there were no intensifiers. With the development of Modern Standard Arabic (MSA) and the spoken colloquial dialects of Arabic, intensifiers emerged. Feodorov (2000) argues that intensifiers came into MSA by means of grammaticalization. Hopper \& Traugott (2003, p. 1) explain that the term refers to "language change that is concerned with such questions as how lexical items and constructions come in certain linguistic contexts to serve grammatical functions or how grammatical items develop new grammatical functions". Kuteva and Heine $(2008$, p. 217) define the process as "the development from lexical to grammatical forms and from grammatical to even more grammatical forms Self-forms are also widely used as intensifiers in Arabic" In this way, it can be claimed that intensifiers are a significant indication of the language change of Arabic.

In her analysis of intensifiers in Arabic, Feodorov (2000) indicates that intensifiers came into Arabic by means of grammaticalization. She explains that the Arabic intensifier "giddan", an adverb meaning "very" can be considered as a gramaticized item. It is derived from the noun "gidd" meaning "force or seriousness in the implementation of an action". The noun evolved to express the high degree of a quality. In its modern use, she adds, the adverb giddan is always placed after an adjective or participle that expresses a quality or property.

\section{Data and Methodology}

The data collected in this study are based on a corpus of contemporary Egyptian and Saudi Arabic from two different sources. These are (1) the Egyptian radio show Ish Sabahak (Live Your Morning) on Nogoum FM Radio Channel and (2) the Saudi radio show Caffeine on Mix FM. The rationale is that the two shows are similar in terms of nature, production, and audience. It is likely then that the selected data will serve the purposes of the study in exploring the role of geographic location in linguistic diversity today. Data was collected from thirty recent episodes of the two shows, aired from July to September, 2016. The use of intensifiers was recorded with both the nationality and gender of the speaker. The participants in this study represent different age groups and different social and ethnic backgrounds. They are both males and females whose first language is Arabic. All of the participants use Egyptian and Saudi Arabic for their everyday interaction. There is no selectivity in data collection. That is, the study will include all the intensifiers used by the participants during the given period so that there is no bias. Ethical issues are also considered. Although the radio show is public and the access is for free, consent has been already obtained from the radio station to use the data whether from the live chats. Privacy of participants is also considered. A frequency analysis will be conducted for the intensifiers and ratios of Egyptian and Saudi speakers will be compared. Linguistic analysis of the intensifiers will also be described. It will be seen also whether there is correlation between sex and the use of intensifiers.

Ish Sabahak is a morning radio daily show that is broadcasted from Sunday to Thursday (the working days in the Arab world) from 07:00 am to 11:00 am. The program reports on the local and international news, currency and gold prices, flight schedules, as well as stock exchange news. It is based on both hosting celebrity guests who are normally actors, actresses, footballers, as well as other well-known people and receiving phone calls as well as social media participations from the show listeners and followers. The program is followed by so many Egyptians around the country.

Mix FM has been broadcasting in the KSA since 2010 and is now the second-highest radio station for listeners across the country. When it was first launched, it targeted the Saudi youth between 16 and 24 years. However, with the rapid success of the station, it now targets listeners of all different ages. Reports indicate that Mix FM is well received by male and female Saudis, whose loyalty has made it the number 2 in Saudi Arabia, with high levels of brand recognition throughout the Kingdom. The rationale of selecting this program is that it is one of the most popular shows in Saudi Arabia and it is followed by millions of Saudi speakers. The level of audience participation is also very high by both male and female speakers.

Caffeine is one of the most widely followed programs. It is a daily radio show from Sunday to Thursday since the weekend in Saudi Arabia is Friday and Saturday. The program is broadcasted from 06:00 am to 10:00 am. The program is based on discussing daily events and topics as well as covering local and international news with the audience either on air or via Twitter. Audience can participate by calling or twitting. Spoken data will be collected from both the audience and show presenters。 


\section{Results}

Results indicate that there are four intensifiers in the speeches and utterances of Egyptian and Saudi speakers. These are giddan, ?awii, marrah, and wajed. The highest frequent intensifier is giddan and it is used in both EA and SA. The intensifiers ?awii and marrah come second and third respectively. The former is exclusively used in EA while the latter is only used in SA. The intensifier wajed is the least and it is used only in SA. This is shown in the figure below.

frequency of intensifiers in EA and SA

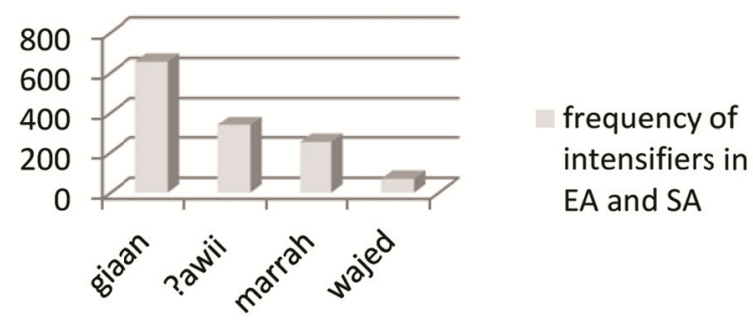

Figure 1. Intensifiers in EA and SA

It is obvious then that there are significant differences between EA and SA in both frequency and type of intensifiers. Results indicate that intensifiers are more frequently used in EA than in SA.

\section{Frequency of intensifiers}

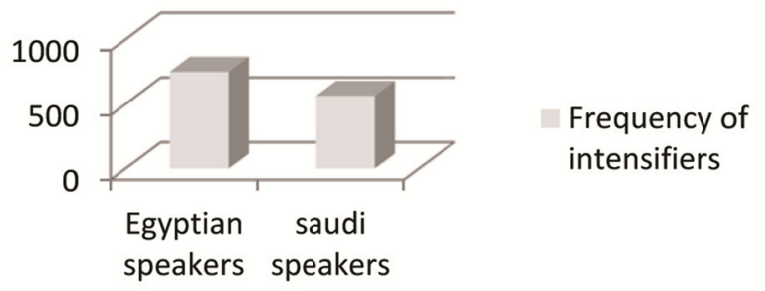

Figure 2. A Frequency analysis of intensifiers in EA and SA

Another interesting finding is that intensifiers are more frequent in the female speeches in both EA and SA. Results show that the intensifier giddan was used 411 times, 185 and 226 fir male and female speakers respectively. The intensifier?awwi was used 337 with the frequency of 142 and 195 for males and females respectively.

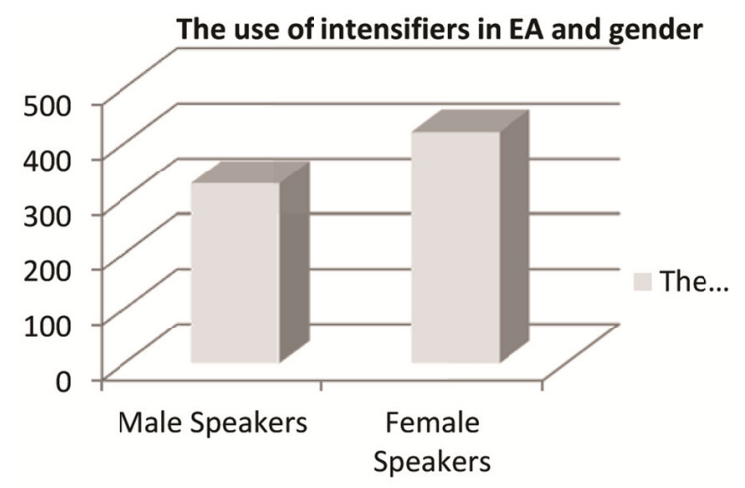

Figure 3. The relationship between the use of intensifiers and gender in EA 
Likewise, female Saudi speakers use intensifiers more frequently than male speakers do. For all the three intensifiers used in SA, female speakers use intensifiers more than male speakers do. The intensifier marrah was used 251 with frequencies of 107 and 144 for male and female speakers respectively; giddan 244 with frequencies of 112 and 132 respectively; and wajed 67 with 31 and 37 respectively.

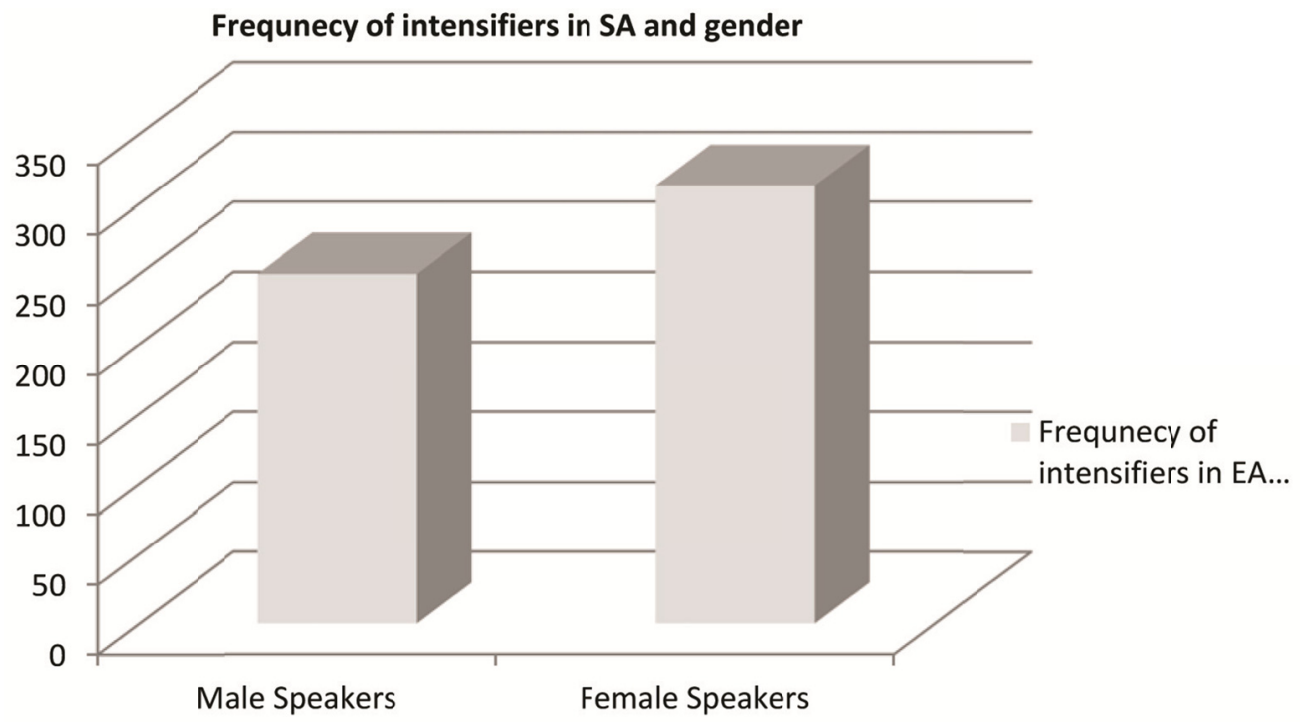

Figure 4. The relationship between the use of intensifiers and gender in EA

\section{Discussions}

As shown above, the intensifier giddan is the most frequently used in both EA and SA. The word giddan is an adverb. It is derived from the noun "gidd" meaning seriousness. It came later to acquire new semantic meanings and it is used now as an intensifier. The word ?awii is an adjective meaning strong. It is pronounced as [awi:] in Cairene Arabic and most Egyptian dialects. However, it is also pronounced as [qawi:] in Modern Standard Arabic (MSA) and as [gawi:] in some colloquial dialects. Through grammaticalization process, a language change took place within the use of the word. The word acquired a new grammatical status. In the same way, the two intensifiers wajed and marrah are nouns that with the development of colloquial dialect of Saudi spoken Arabic acquired new semantic meanings and grammatical functions. The former is derived from the verb wajada meaning, a past form meaning found. Wajed then is the person who finds something. The word developed in colloquial Saudi Arabic to mean something that is found in plenty. It is now used in conjunction with adjectives to intensify the meaning. The implication is that the word came to acquire new semantic meanings and grammatical functions. Similarly, the word marrah is a noun originally meaning once. In colloquial spoken Saudi Arabic, it has come to mean very or so much. It is now used as an intensifier in conjunction with adjectives.

The most widely used intensifier in EA and SA is marrah. This indicates that SA still has its unique features which are even different from MSA.

It is also obvious that the intensifier ?awii is exclusively used in EA while the two intensifiers wajed and marrah are only used in SA. An interesting feature with the use of intensifiers is that in EA, speakers tend to increase the effect by repeating the intensifier. It is very common in EA to find such utterances

1). Elfilm kan kuwayyes giddan giddan.

The-movie was good very very

"The movie was very good".

2). Elrewaya gazzaba ?awii ?awii ?awii.

The novel attractive very very very

"The novel was very attractive" 
One final observation about the data is that female speakers in both EA and SA tended to use intensifiers more frequently than male speakers. This accounts for the different communicative behavior of men and women. In the use of intensifiers, women speakers tend to put more emphatic stress in their utterances. According to Lakoff (1975), the frequent use of intensifiers by female speakers can be attributed to women's lack of power and assertiveness. It can be claimed then that there are significant differences between EA and SA in the use of intensifiers in terms of frequency and type. Furthermore, linguistic analysis of the data shows that the linguistic structures of intensifiers are different in EA and SA. These are shown as follows.

\section{Contrasts in Syntactic Positions of Intensifiers}

Intensifiers in SA and in EA may take different structures. In SA, we can find two different word order patterns associated with different meaning, while such a distinction of word order patterns is not available in EA. More precisely, the syntactic criterion differentiates uses of intensifiers in SA, uses of intensifiers in EA are not indicated by word order. Therefore, the paper shall make a difference between the structures of intensifiers in the two languages before moving towards making any further comparison.

As far as distribution is concerned, intensifiers in EA occur always in adjunct position; their position is right adjacent to the modified phrase (consider the contrast between (1a) and (1b). Intensifiers in SA can follow or precede the modified phrase (consider examples (2a) and (2b):

$$
\begin{aligned}
& \text { 3a). elgaw enaharda har ?awii } \\
& \text { the-weather today hot very } \\
& \text { "It is very hot today" } \\
& \text { b.* elgaw ?awii har } \\
& \text { the-weather very hot } \\
& \text { "The car is very beautiful" } \\
& \text { 4a). assiaarah hilwa marrah (SA) } \\
& \text { the-car very beautiful } \\
& \text { "the car is very beautiful" } \\
& \text { b.* assiaarah marrah hilwa } \\
& \text { the-car very beautiful } \\
& \text { "The car is very beautiful" }
\end{aligned}
$$

However, in both languages, the intensifiers can be assumed as dominated by the verbal projection. Assuming intensifiers are adverbs that are placed right of modified phrases, examples (3a-b) suggest that intensifiers in EA often remain in their thematic position, and thus, there wouldn't be any additional meaning associated with their syntactic position. Given the argument that raising a constituent is sometimes seen as a semantic notion (Bresnan, 1982) and given the fact that intensifiers in SA can raise to a higher position (4b), there should be an additional meaning associated with the fronted intensifier. This strategy is used by Saudi speakers to emphasize the pragmatic significance that is revealed by the speaker's intention to draw his recipient's attention to particular part of the clause.

\section{Contrasts in phonological aspects}

The second line of differences is phonological. It is widely assumed that there is a relationship between the phonological placement of phrasal stress and the discourse-related concept of new information. The assignment of stress plays a role in drawing the attention of the speaker's addressee to a particular part of the sentence. While intensifiers in EA do not receive a primary stress, intensifiers in SA can be stressed. A stressed intensifier might predict powerfulness, whereas a non-stressed intensifier might function as a filler. Consider the following pair of examples (heavy stress is indicated by capital letters):
5a). hathaa hiluu marrah
this.sm sweet.sm very
"This is very sweet"
b. hatha hiluu maRRah
this.sm sweet.sm VERY 
"This is very sweet"

In (5b), the intensifier receives a focal stress to convey the higher degree in comparing with its counterpart in $(5 a)$.

To sum up, in SA, intensifiers can be classified on the basis of word order patterns. The conclusive factor for interpretation of intensifiers in SA is the one-to-one relationship between the word order patterns and the intensifiers meaning. The syntactic position plays a major role in determining the intensifiers meaning. In EA, on the other hand, intensifiers cannot be classified in the same way as in SA depending on their syntactic position as they often tend to follow the VP. The second line of differences is phonological, while intensifiers in EA cannot make a combination of stress and meaning, those in SA can do. Such stressing and focusing are mostly connected with a semantic affect.

\section{More on the intensifier marrah}

This intensifier differs from other intensifiers in that it can be introduced by the preposition (be-) and article (l-) as in bi-l-marrah. The behavior of marrah-form is strongly influenced by the nature of predicates. It shows a much higher percentage of occurrences.

The preposition $b i$ - is not necessary used as markers of location or direction, but it has a wide range of uses including emphasizing (Ryding, 2005, p. 367). Be- is sometimes co-occur with the article $l$ - to inflect the degree (comparative and superlative). Likewise, the article $l$ - is not always used as a definite article, but it can be used as a superlatives and comparative form to scale attributes. Strictly speaking, it is introduced the intensifier in SA to express the concept of "majority". Consider the followings:
6). 1-fuTuur
hiluu
bi-l-marrah
the-breakfast delicious pre-def-very
"The breakfast is very delicious".

In terms of its position in the clause, it normally occurs at the end of the phrase it modifies (6), but it can precede it as in below:
7). 1-fuTuur
bi-1-marrah hiluu
the-breakfast pre-def-very delicious
"The breakfast is very delicious".

The findings of the study therefore agree with the mainstream in sociolinguistic studies that geography and geographic location has a considerable impact on language use. People come to use language differently when they are geographically separated even with the increasing contact between people due to the unprecedented development in communication channels (Eisenstein, 2014; Hong et al., 2012; Pavalanathan \& Eisenstein, 2015). Regional dialects come out of the standard language when speakers of the same language come to live in different geographic locations. In our case, intensifiers vocabulary deviated from the standard norm and took different forms in both Egyptian and Saudi Arabic. The case is that in spite of the widespread of social media communication in an unprecedented way, people still use language differently. In their experimental study of geographic location and language modeling, Hong et al. (2012) argue that linguistic maps can be identified by means of discovering the geographical spots of Twitter users. Similarly, Eisenstein (2014) stresses that posts on Twitter reflect some well-known regionalisms. The findings of his study of over 380,000 tweets in the United States reveal that people in Washington, for example, used different words and spellings to people in New York.

There is empirical evidence then that geographic location is a considerable factor in language change. The findings of the study agree with the established sociolinguistic theories that language changes over time based on geography. In spite of the global changes which have their implications clearly on language use, linguistic differences are still intertwined with distance or geographic location (Takhteyeva et al., 2012). Distance is still a considerable factor in linguistic diversity.

\section{Conclusion}

This study investigated the use of intensifiers by Egyptian and Saudi speakers in recent episodes of two radio shows in Egypt and Saudi Arabia. Data was collected from 30 recent episodes of two Egyptian and Saudi radio shows, aired from June to August 2016. Results indicate clearly that there are significant linguistic differences in the way Egyptian and Saudi speakers use intensifiers. These differences are related to frequency, type, and linguistic structure. It can be concluded then that geographic location is still considered an important factor in linguistic diversity in the spoken dialects of Arabic in spite of the increasing interaction between the speakers of 
the two dialects. It can be claimed that the use of intensifiers is closely related to cultural patterns that are shaped over the years.

\section{References}

Algeo, J. (2006). British or American English?: a handbook of word and grammar patterns. Cambridge: Cambridge University Press. https://doi.org/10.1017/CBO9780511607240

Algeo, J. (2010). The Cambridge History of the English Language, VI. English in North America. Cambride; New York: Cambridge University Press.

Auer, P. (2013). The Geography of Language: Steps toward a New Approach. FRAGL, 16, 1-39.

Auer, P., \& Schmidt, E. (Eds.). (2010). Language and Space: An International Handbook of Linguistic Variation (Vol. 1, Theories and Methods). Berlin; New York: De Gruyter Mouton.

Beal, J. C. (2010). An introduction to regional Englishes: dialect variation in England. Edinburgh: Edinburgh University Press.

Bresnan, J. (1982). Control and complementation. Linguistic Inquiry, 13, 343-434.

Chambers, J. K., Trudgill, P., \& Schilling-Estes, N. (2013). The handbook of language variation and change. Malden, Mass; Oxford: Blackwell. https://doi.org/10.1002/9781118335598

Davies, D. (2005). Varieties of modern English: an introduction. Harlow: Longman.

Eisenstein, J. (2014). Identifying regional dialects in online social media. Proceedings of the Association for Computational Linguistics (ACL), 1365-1374.

Everett, C. (2013). Evidence for direct geographic influences on linguistic sounds: The case of ejectives. PLoS ONE, 8(6). https://doi.org/10.1371/journal.pone.0065275

Everett, C., Blasi, D., \& Roberts, S. (2015). Climate, vocal folds, and tonal languages: Connecting the physiological and geographic dots. Proceedings of the National Academy of Sciences, 112, 1322-1327. https://doi.org/10.1073/pnas.1417413112

Gast, V. (2006). The grammar of identity: intensifiers and reflexives in Germanic languages. London: Routledge.

Gavin, M. C., Botero, C. A., Bowern, C., Colwell, R. K., \& Robert, M. D. (2013). Toward a Mechanistic Understanding of Linguistic Diversity. BioScience, 63(7), 524-535. https://doi.org/10.1525/bio.2013.63.7.6

Gibson, M. (2103). Dialect Levelling in Tunisian Arabic: Towards a New Spoken Standard. Language Contact and Language Conflict in Arabic. In A. Rouchdy (Ed.), Language Contact and Language Conflict in Arabic (pp. 24-40). London: Routledge.

Gülzow, I. (2006). The acquisition of intensifiers: emphatic reflexives in English and German child language. Berlin; N.Y.: Mouton de Gruyter.

Hargraves, O. (2003). Mighty fine words and smashing expressions: making sense of transatlantic English. Oxford: Oxford University Press.

Holmes, J. (2008). An introduction to sociolinguistics (3rd ed.). Harlow: Longman.

Hong, L., Ahmed, A., Gurumurthy, S., Smola, A., \& Tsioutsiouliklis, K. (2012). Discovering Geographical Topics in The Twitter Stream. Proceedings of the 21st international conference on World Wide Web, 769-778. https://doi.org/10.1145/2187836.2187940

Hughes, A., Trudgill, P., \& Watt, D. J. L. (2015). English accents and dialects: an introduction to social and regional varieties of English in the British Isles (5th ed.). London; New York: Routledge.

Klemola, J. (2013). English as a contact language in the British Isles. In D. Schreier \& M. Hundt (Eds.), English as a contact language (pp. 75-88). Cambridge ; New York: Cambridge University Press.

Lakoff, R. (1975). Language and Woman's Place. Harper and Row.

Lass, R. (1997). Historical linguistics and language change. Cambridge: Cambridge University Press. https://doi.org/10.1017/CBO9780511620928

Maffi, L. (2005). Linguistic, cultural, and biological diversity. Annual Review of Anthropology, 34, 599-617. https://doi.org/10.1146/annurev.anthro.34.081804.120437

Matras, Y. (2009). Language contact. Cambridge: Cambridge University Press. https://doi.org/10.1017/CBO9780511809873 
McArthur, T. (2002). The Oxford guide to world English. Oxford: Oxford University Press.

Mubarak, H., \& Darwish, K. (2014). Using Twitter to collect a multi-dialectal corpus of Arabic. Proceedings of the EMNLP 2014 Workshop on Arabic Natural Language Processing (ANLP), 1-7. https://doi.org/10.3115/v1/W14-3601

Pavalanathan, U., \& Eisenstein, J. (2015). Audience-modulated variation in online social media. American Speech, 90(2), 187-213. https://doi.org/10.1215/00031283-3130324

Peters, P. (2007). The Cambridge guide to Australian English usage (2nd ed.). Cambridge: Cambridge University Press. https://doi.org/10.1017/cbo9780511481253

Quirk, R., \& Crystal, D. (1985). A Comprehensive grammar of the English language. London: Longman.

Rallings, J. (2015). Youth and the internet: a guide for policy makers. Essex, UK: Barnardo's

Romero, S. (2012). This Is So Cool! A Comparative Study on Intensifiers in British and American English. University of Tampere, Tampere, Finland.

Ryding, K. C. (2005). A reference grammar of modern standard Arabic. Cambridge: Cambridge University Press.

Schreier, D., \& Hundt, M. (2013). English as a contact language. Cambridge; New York: Cambridge University Press.

Siemund, P. (2000). Intensifiers in English and German: a comparison. London: Routledge. https://doi.org/10.4324/9780203279540

Siemund, P. (2003). Varieties of English from a cross-linguistic perspective: Intensifiers and reflexives. In B. Mondorf (Ed.), Determinants of Grammatical Variation in English (pp. 479-506). Berlin: Mouton De Gruyter. https://doi.org/10.1515/9783110900019.479

Syal, P., \& Jindal, D. V. (2007). An Introduction to Linguistics: Language, Grammar and Semantics.

Tadmor, U. (2009). Loanwords in the world's languages: Findings and results. In H. M. a. U. Tadmor (Ed.), Loanwords in the World's Languages: A Comparative Handbook (pp. 55-75). Berlin: De Gruyter Mouton. https://doi.org/10.1515/9783110218442.55

Tagliamonte, S., \& Roberts, C. (2005). SO WEIRD; SO COOL; SO INNOVATIVE: THE USE OF INTENSIFIERS IN THE TELEVISION SERIES FRIENDS. American Speech, 80(3), 280-300. https://doi.org/10.1215/00031283-80-3-280

Takhteyeva, Y., Gruzdb, A., \& Wellman, B. (2012). Geography of Twitter networks. Social Networks, 34, 73-81. https://doi.org/10.1016/j.socnet.2011.05.006

Trousdale, G. (2010). An introduction to English sociolinguistics. Edinburgh: Edinburgh University Press.

Trudgill, P., \& Hannah, J. (2008). International English: a guide to varieties of standard English (5th ed.). London: Hodder Education.

Wardhaugh, R. (2006). An introduction to sociolinguistics (5th ed.). Oxford: Blackwell Publishing.

Wardhaugh, R., \& Fuller, J. (2015). An introduction to sociolinguistics (7th ed.). Sussex: John Wiley \& Sons, Inc.

Wolfram, W., \& Schilling, N. (2016). American English: Dialects and Variation (3rd ed.). Oxford: Blackwell.

\section{Copyrights}

Copyright for this article is retained by the author(s), with first publication rights granted to the journal.

This is an open-access article distributed under the terms and conditions of the Creative Commons Attribution license (http://creativecommons.org/licenses/by/4.0/). 